\title{
Effect of Shoulder Protraction Exercise on the Supine position for Selective Activation of the Serratus Anterior according to Weight in Winging Scapula
}

\author{
TaeHo Kim', SungYoung, Kim², HanKyu Park ${ }^{3}$ \\ 'Department of Physical Therapy, College of Rehabilitation Science, Daegu University; ${ }^{2}$ Department of Physical Therapy, Graduate School of Daegu \\ University; ${ }^{3}$ Department of Physical Therapy, Dong-ju College, Busan, Korea
}

Purpose: This study investigated the effects of shoulder protraction exercise according to weight by examining the surface electromyography (EMG) amplitude in the serratus anterior (SA), upper trapezius (UT), and pectoralis major (PM) as well as the activity ratio of each muscle.

Methods: Twenty three winging scapula subjects participated in the study. The subjects performed scapula protraction at shoulder $90^{\circ}$ flexion and $60^{\circ}$ horizontal abduction with up to four (none, $1 \mathrm{~kg}, 1.5 \mathrm{~kg}$, and $2 \mathrm{~kg}$ ) dumbbells in the supine position. The EMG data were collected from the dominant side muscles during a shoulder protraction exercise according to weight in the supine position. One way repeated measures analysis of variance (ANOVA) was used to compare the normalized activities of the SA, UT, and PM and the ratios of $\mathrm{PM} / \mathrm{SA}$ and UT/SA.

Results: The results showed that the activities of both the SA and UT were highest for the shoulder protraction exercise at $2 \mathrm{~kg}$ in the supine position. The UT/SA ratio also was the lowest for exercise at $2 \mathrm{~kg}$. On the other hand, the activities of both the UT and PM/SA ratio were similar under all conditions.

Conclusion: These results show that there is a need to selectively strengthen the SA muscle in the case of patients with the shoulder dysfunction. In particular, it is necessary to weigh $2 \mathrm{~kg}$ when performing shoulder protraction exercises in the supine position to activate the SA muscle in patients with a winging scapula.

Keywords: Scapula protraction, Serratus anterior, Upper trapezius, Pectoralis major

\section{서 론}

우리 인체 중에서 큰 자유도(degrees of freedom)를 가지고 있는 어깨 관절은 가장 큰 운동성을 가지고 있지만 반대로 가장 큰 불안정성의 요소를 지닌 손상 받기 쉬운 관절 중에 하나이다. ${ }^{1}$ 어깨 관절의 대표 적인 손상은 어깨가슴(scapulothoracic) 근육들의 전반적인 약화로 인 한 불균형으로 운동범위의 감소가 주로 발생하며 특히 위 등세모근 (upper trapezius)의 과도한 활성과 앞톱니근(serrtus anterior)의 약화는 비정상적인 어깨뼈의 움직임을 일으킨다. ${ }^{2}$ 이와 같이 어깨에는 불안 정성을 감소시키고 안정성을 제공하며 정상적인 움직임을 위하여 안 정화 근육(stabilizermuscle) 즉 앞톱니근, 위 등세모근, 돌림근띠(rotator cuff), 그리고 어깨세모근(deltoid muscle)들이 발달되어 있다. ${ }^{3}$
그 중에서도 앞톱니근은 어깨뼈 안정화에 있어 가장 중요한 역할 을 하고 어깨뼈 내밈(protaction)과 위쪽 돌림(upward rotation) 작용을 하며 위팔과 어깨뼈 사이의 위치와 움직임을 조절한다. ${ }^{4}$ 또한 협동근 (synergist)으로 아래 등세모근(lower trapezius)이 어깨뼈의 적절한 위 치를 유지하며 동적인 안정성을 제공한다. ${ }^{5}$ 만약 이러한 근육들의 불 균형 즉 앞톱니근의 기능저하와 위 등세모근의 과도한 활성으로 인 하여 어깨에 기능장애가 발생하게 되면 어깨충돌(shoulder impingement) 뿐 아니라 날개 어깨뼈(winging scapula)와 같은 정렬부정(malalignment)으로 인한 비정상적인 움직임 패턴이 발생한다고 하였 다. ${ }^{2,6,7}$ 따라서 어깨충돌 및 날개 어깨뼈와 같은 비정상적인 어깨 기능 장애를 해결하기 위하여 앞톱니근의 선택적인 활성화를 위한 운동 중재방법들의 연구가 꾸준히 이루어지고 있다.2,8-10 
어깨 손상 환자들에게 과활동성 근육들을 억제하고 약화된 근육 들의 강화를 통하여 어깨 손상을 일으키는 근육들의 불균형 감소를 확인하였고 ${ }^{10}$ 외부 저항을 이용한 같은길이 수축(isometric contraction)의 어깨 굽힘 운동시 어깨 안정화에 기여하는 돌림근띠들의 활 성화를 확인하였다." 그리고 위 등세모근과 앞톱니근의 활성도 비율 측면에서 위 등세모근의 낮은 활성도와 앞톱니근의 높은 활성도를 이끌어 낼 수 있는 운동방법을 권장한다고 하였다. ${ }^{2}$ 또 다른 선행연 구들에서도 바로 선 자세에서 시행한 어깨 내밈 운동을 다양한 벌림 각도와 외부저항 그리고 테이핑을 이용한 운동을 통하여 어깨 주변 근육들의 활성도를 확인하였다.12-14 또한 가장 효과적인 앞톱니근의 활성을 이끌어 내기 위하여 표준화된 푸쉬업 플러스(standard push up plus)운동을 추천하며 이후에도 여러가지 변형된 푸쉬업 플러스 운동 들이 임상에서 널리 적용 되고 있다.15,16

하지만 정상인을 대상으로 시행한 열린 사슬(open chain)인 바로 누운 자세에서 어깨 내밈 운동과 닫힌 사슬(close chain)인 네발기기 (quadripedal) 자세에서 푸쉬업 운동이 어깨 주변 근육들의 활성도를 비교한 연구에서는 오히려 열린 사슬 자세인 바로 누운 자세에서 높 은 앞톱니근의 선택적인 활성도와 함께 위 등세모근과 큰가슴근의 활성도 비율에서 유의한 차이를 확인하였다. ${ }^{17}$ 그러나 위 연구는 정 상 성인을 대상으로 시행하였기에 비정상적인 움직임과 근육 불균형 을 가진 날개 어깨뼈 환자들을 대상으로 실시할 필요가 있다는 제한 점을 토대로 본 연구는 열린 사슬인 바로 누운 자세에서 어깨 내밈 운동을 할 때 $90^{\circ}$ 어깨 굽힘과 $60^{\circ}$ 어깨 벌림 위치에서 외부 저항인 none, $1 \mathrm{~kg}, 1.5 \mathrm{~kg}, 2 \mathrm{~kg}$ 덤벨을 이용하여 앞톱니근, 위 등세모근, 그리고 큰가슴근의 활성도와 두 근육들과 앞톱니근의 활성도 비율을 비교 하여 바로 누운 자세에서 어깨 내밈 운동시 본 연구의 외부 저항으로 사용한 none, $1 \mathrm{~kg}, 1.5 \mathrm{~kg}, 2 \mathrm{~kg}$ 중에서 가장 효과적인 무게를 확인하여 날개 어깨뼈에 효율적인 운동방법을 제시하고자 하였다.

\section{연구 방법}

\section{1. 연구대상}

본 연구는 경상북도 D대학교에 재학 중인 학생들을 대상으로 실험 전에 연구의 목적과 방법에 대해 충분히 설명을 듣고 자발적으로 동 의한 자를 대상으로 추가적인 날개 어깨뼈 진단방법을 통한 23 명의 대상자들(남자 10명, 여자 13명)을 선정하였다. 대상자들은 근육뼈대 계 또는 신경계에 문제가 없으며 어깨와 관련된 질환이나 치료의 경 험이 없고 규칙적인 운동을 하지 않는 자들이며 어깨 운동 범위에 제 한이 없는 자들로 선정하였다. 특히 날개 어깨뼈 측정은 바로 선 자세 에서 양쪽 어깨뼈 안쪽면이 $1 \mathrm{~cm}$ 이상 들리는 자를 대상으로 엎드린 자세에서도 어깨뼈 안쪽면이 $3 \mathrm{~cm}$ 이상 들리는 자들을 최종적으로
선정하였다. ${ }^{18}$ 대상자들의 일반적인 특성은 나이 $22.8 \pm 1.9$ 세, 키 168.5 $\pm 10.4 \mathrm{~cm}$, 몸무게 $63.1 \pm 13.5 \mathrm{~kg}$ 이며 대상자 모두 오른쪽을 우세손으 로 사용하였다. 본 연구는 D대학교 생명윤리위원회의 승인을 받았 다(1040621-201707-HR-014-02).

\section{2. 실험방법}

1) 측정도구

(1)표면 근전도

어깨 내밈 운동시 우세측인 오른쪽 근육들의 근활성도는 무선 표면근 전도(TeleMyo DTS, Noraxon, USA)를 이용하여 측정하였다. 1,000 Hz 표본 추출률(sampling data)과 20-400 Hz의 대역통과필터(band pass filter)를 사용하였으며 $60 \mathrm{~Hz}$ 의 노치필터(notch filter)를 사용하였다. 근전도 도자를 부착하기 전에 부착 부위에 제모와 함께 사포를 이용 하여 각질층을 제거하였으며 알코올 솜으로 소독하였다. 도자는 앞 톱니근은 근 중앙부위 즉 오른쪽 5 번째 갈비뼈의 중앙 겨드랑이 부 위에 부착하였고 위 등세모근은 제 7 목뼈 가시돌기와 봉우리 가쪽 의 제일 중앙 근육 힘살에 부착하였으며 큰가슴근은 겨드랑이 주름 에서 안쪽으로 $2 \mathrm{~cm}$ 지점에 부착하였다. ${ }^{19}$ 측정하기 전에 최대 수의적 같은길이 수축(maximal voluntary isometric contraction, MVIC)으로 앞톱니근과 위 등세모근, 그리고 큰가슴근의 활성화를 정규화하였 다. 연구자는 대상자들에게 각 근육의 근력검사 방법으로 최대 저항 으로 5 초간 유지하라고 지시하였다. MVIC의 측정 자세는 Kendall의 근력검사방법을 이용하였다. ${ }^{20}$ 본 연구에서 근전도 측정값은 우세측 인 오른쪽의 근육들을 대상으로 처음과 끝의 1 초를 제외한 중간 3 초 를 결과값으로 사용하였다. MVIC 값은 3회 평균 실효평균값(root mean square)을 사용하였다. 평균 $\mathrm{EMG}$ 측정값은 \%MVIC로 백분율 화 하였다. 근 피로도를 고려하여 각 측정마다 3 분간의 휴식시간을 제공하였다. 앞톱니근의 선택적인 활성도를 평가하기 위하여 앞톱니 근과 위 등세모근의 비와 앞톱니근과 큰가슴근의 비를 계산하였다.

\section{(2)관절 각도계와 전자 디지털 캘리퍼}

바로 누운 자세에서 어깨 $90^{\circ}$ 굽힘 각도 측정과 어깨 내밈 운동시 어깨 벌림 각도 $60^{\circ}$ 를 유지하기 위하여 관절 각도계를 사용하였다. 전자 디 지털 캘리퍼(Digital caliper, MITUTOYO, Japan)를 이용하여 바로 선 자 세와 네발자세인 푸쉬업 자세에서 대상자들의 날개 어깨뼈의 정도를 측정하기 위하여 어깨뼈 중간 안쪽면에 캘리퍼를 가져다 놓고 등뼈의 가시돌기 위로 게이지를 넣어서 화면에 나타나는 수치를 확인하였다.

\section{2)실험과정}

대상자들은 바로 누운 자세에서 어깨뼈의 스캡션(scaption) 위치인 어 깨 $90^{\circ}$ 굽힘과 함께 $60^{\circ}$ 수평 벌림을 한 위치에 고정 바(target-bar)를 
설치하여 대상자들이 운동을 할 때 벌림의 각도를 일정하게 유지하 게 하였다. 이때 외부 저항인 덤벨 무게는 none, $1 \mathrm{~kg}, 1.5 \mathrm{~kg}, 2 \mathrm{~kg}$ 를 번 갈아 들면서 내밈 운동을 시행하였다. 저항 순서는 학습효과를 배제 하기 위하여 무작위로 각각의 무게가 적힌카드를 상자에 넣어 대상 자들이 직접 뽑게하여 나오는 무게 순서대로 시행하였으며 각 무게 마다 30 분간의 휴식시간을 제공하였다. 모든 운동은 대상자들이 익 숙해지도록 충분한 연습과정을 거쳤고 무작위로 나오는 덤벨의 무게 를 들고 어깨 내밈 운동은 5 초간 유지하고 5 초 휴식을 기준으로 3 회 측정하여 근전도의 평균값을 채택하였다(Figure 1).

\section{3)자료분석}

자료의 분석은 SPSS version 22.0 프로그램을 사용하였다. 자료의 정 규성 검정은 Shapiro-Wilk로 확인하였으며 어깨 $60^{\circ}$ 벌림 위치에서 무 게에 따른 앞톱니근, 위 등세모근, 그리고 큰가슴근의 활성도와 무게 에 따른 위 등세모근/앞톱니근 그리고 큰가슴근/앞톱니근의 활성도 비율을 비교하기 위하여 일원 배치 분산분석(one way repeated ANO$\mathrm{VA})$ 을 사용하였다. 사후분석으로 본페로니(Bonferroni)를 이용하였 다. 통계학적인 유의수준은 0.05 로 하였다.

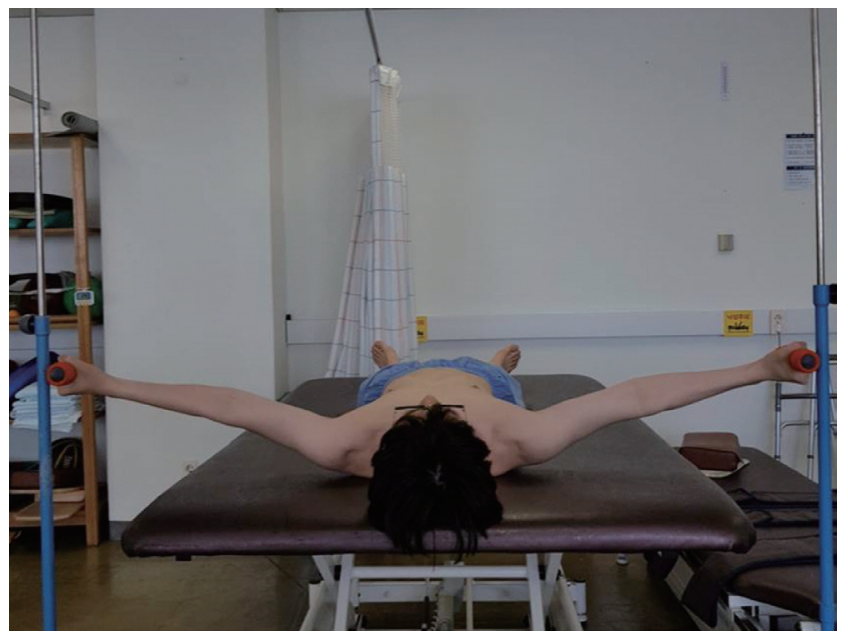

Figure 1. Shoulder protraction exercise with weight $1 \mathrm{~kg}$ at $60^{\circ}$ shoulder abduction

\section{결 과}

\section{1. 무게에 따른 각 근육들의 활성도 비교}

무게에 따른 앞톱니근의 활성도를 비교한 결과 무게가 증가할수록 근활성도가 증가하였으며 유의한 차이가 있었다(Table 1)(Figure 2) $(\mathrm{p}<0.05)$. 사후분석 결과 앞톱니근은 $2 \mathrm{~kg}$ 에서 가장 높은 근활성도를 확인하였다. 큰가슴근 역시 무게가 증가할수록 근활성도가 증가하 였으며 유의한 차이가 있었다 $(\mathrm{p}<0.05)$. 사후분석 결과 $2 \mathrm{~kg}$ 에서 가장 높은 근활성도를 확인하였다. 위 등세모근은 무게가 증가하더라도 일정한 근활성도를 보였으며 유의한 차이가 없었다 $(\mathrm{p}>0.05)$.

\section{2. 무게에 따른 각 근육들간의 비율 비교}

무게에 따른 큰가슴근과 앞톱니근의 비율을 비교한 결과 유의한 차 이가 없었다(Table 1)(Figure 2)(p>0.05). 하지만 위 등세모근과 앞톱니 근의 비율 비교에서는 무게가 증가할수록 일정한 비율의 감소를 확 인하였으며 유의한 차이를 확인하였다 $(\mathrm{p}<0.05)$. 사후분석 결과 $2 \mathrm{~kg}$ 에서 가장 낮은 활성도 비율을 확인할 수 있었다.

\section{고 찰}

어깨가슴관절의 기능장애중 대표적인 불안정성 및 근육 불균형의 결과로 발생하는 날개 어깨뼈를 해결하기 위하여 선택적인 앞톱니근

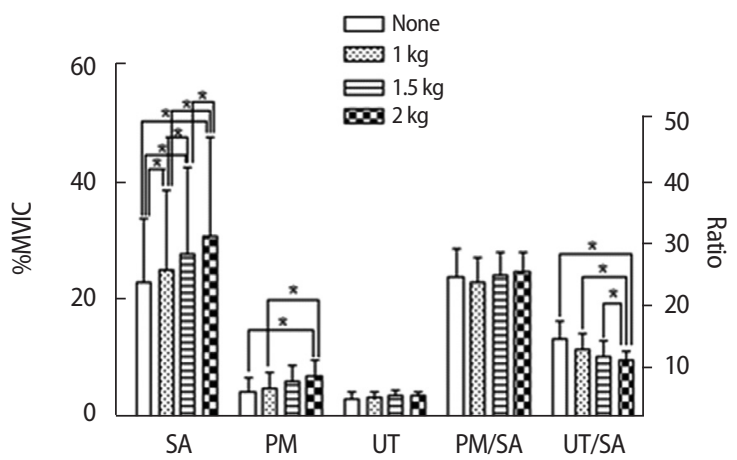

Figure 2. The graph is a comparison of each muscle activities and ratio

Table 1. Comparison of muscle activities according to the weight of each muscle and PM/SA and UP/SA ratio

\begin{tabular}{|c|c|c|c|c|c|c|}
\hline \multirow{2}{*}{ Muscle } & \multicolumn{4}{|c|}{ Weight } & \multirow{2}{*}{$\mathrm{F}$} & \multirow{2}{*}{$p$} \\
\hline & None & $1 \mathrm{~kg}$ & $1.5 \mathrm{~kg}$ & $2 \mathrm{~kg}$ & & \\
\hline SA (\%MVIC) & $30.91 \pm 15.40$ & $35.01 \pm 15.67$ & $38.57 \pm 17.61$ & $43.00 \pm 19.24$ & 44.137 & $0.000^{*}$ \\
\hline PM (\%MVIC) & $6.45 \pm 2.79$ & $7.32 \pm 3.54$ & $8.39 \pm 4.63$ & $9.31 \pm 5.40$ & 7.987 & $0.003^{*}$ \\
\hline UT (\%MVIC) & $4.36 \pm 2.82$ & $4.54 \pm 3.25$ & $4.60 \pm 3.38$ & $4.52 \pm 3.47$ & 0.453 & 0.657 \\
\hline PM/SA ratio & $27.49 \pm 20.92$ & $26.15 \pm 20.20$ & $27.29 \pm 21.67$ & $27.49 \pm 22.79$ & 0.167 & 0.777 \\
\hline UT/SA ratio & $15.69 \pm 11.49$ & $13.85 \pm 10.04$ & $12.61 \pm 8.65$ & $11.25 \pm 8.84$ & 10.379 & $0.000^{*}$ \\
\hline
\end{tabular}

${ }^{*} \mathrm{p}<.05$, SA: serratus anterior, PM: pectoralis major, UT: upper trapezius. 
의 강화 운동방법에 대해 수많은 연구들이 이루어지고 있으며 그 중 에서도 푸쉬업 운동과 함께 무릎, 팔꿉, 그리고 벽을 이용한 다양한 수정된 푸쉬업 운동들이 앞톱니근의 강화를 위하여 사용되고 있 다.28,15,21 하지만 정상 성인을 대상으로 열린 사슬과 닫힌 사슬의 운동 자세를 통하여 앞톱니근의 활성화를 비교한 연구와 앞톱니근 보다 비교적 낮은 위 등세모근의 활성화를 확인한 바로 누운 자세에서 효 율적인 앞톱니근의 활성화를 확인한 연구를 통하여 본 연구는 열린 사슬 운동방법인 바로 누운 자세에서 어깨 $90^{\circ}$ 굽힘과 $60^{\circ}$ 벌림 상태 에서 4 가지 덤벨 무게에 따른 앞톱니근, 큰가슴근, 그리고 위 등세모 근의 활성도와각 근육들간의 비율을 비교하고자 진행하였다.12,17

본 연구 결과 무게가 증가할수록 앞톱니근의 활성도가 증가하였 다. 그 이유는 먼저 앞톱니근의 해부학적인 근육의 위치에 의한 작용 인 손 뻗기나 어깨 내밀기 동작을 할 때 덤벨에 의한 외부 저항과 중 력을 이겨내는 내밈 동작시에 무게가 증가할수록 앞톱니근의 보다 높은 활성화를 이끌어 낸 것으로 생각된다. 아울러 바로 누운 자세에 서 어깨 내밈 동작시에 무게가 증가함에 따라 어깨의 불안정성을 증 가시켜 이를 보상하기 위하여 앞톱니근의 높은 활성을 가지고 온 것 으로 생각된다.22

큰가슴근은 none과 $1 \mathrm{~kg}$ 보다 $2 \mathrm{~kg}$ 에서 약간의 증가된 활성도를 보 이며 유의한 차이가 있었다. 하지만 앞톱니근과 비교를 하면 상대적 으로 활성도가 낮게 나타났다. ${ }^{23}$ 이는 앞톱니근의 선택적인 활성화를 위하여 큰가슴근의 낮은 활성도를 확인한 기존 선행 연구에서 알 수 있듯이 본 연구와 차이점은 열린 사슬과 닫힌 사슬의 자세적인 차이 점으로 생각된다. ${ }^{24}$ 내밈의 협동근으로 작용하는 큰가슴근은 본 연 구의 운동방법인 바로 누운 자세에서 어깨 내밈 운동시 특히 $2 \mathrm{~kg}$ 저 항 때 어깨 주위 불안정성과 외부 저항의 증가로 $60^{\circ}$ 의 벌림 각도를 유지하며 어깨 내밈 동작을 하기 위해 큰가슴근의 활성이 약간 증가 한 것으로 생각된다. ${ }^{25}$

위 등세모근은 무게에 따라 유의한 차이가 없었다. 기존 선행 연구 에서 바로 누운 자세에서 어깨관절 각도에 따른 어깨 내밈 운동시 위 등세모근의 활성도는 차이가 없었다. ${ }^{12}$ 또한 건강한 성인을 대상으로 실시한 위팔 굽힘 각도에 따른 어깨 주변 근육의 활성도를 확인한 연 구에서도 같은 결과를 확인하였다.22 따라서 날개 어깨뼈 운동에 있 어서 어깨뼈를 올리고(elevation) 목을 폄(extension)하며 수축하는 반 대 방향으로 목을 회전(rotation)시키는 위 등세모근의 억제 운동방법 은 날개 어깨뼈를 교정하는데 있어 중요한 역할을 하는 앞톱니근 강 화에 상당히 중요한 부분이라고 하였다. ${ }^{10}$

각 근육들간의 비율을 비교한 결과에서 큰가슴근과 앞톱니근의 비에서는 유의한 차이가 없었다. 이는 바로 누운 자세에서 중력과 외 부 저항에 따른 어깨 내밈 운동 시작 자세를 유지하기 위한 큰가슴근 의 편심성 수축(eccentric contraction)의 영향으로 생각이 되며, ${ }^{26}$ 이로
인한 위 등세모근 보다 상대적으로 증가한 큰가슴근의 활성은 앞톱 니근과의 비율 비교에서 비효율적으로 나타난 것으로 생각된다. 위 등세모근과 앞톱니근의 비에서는 유의한 차이가 있었다. 특히 무게 가 증가할수록 일정하게 비율이 감소한 것을 확인할 수 있었다. 이것 은 본 연구의 바로 누운 자세에서 어깨 내밈 운동이 위 등세모근을 억제하고 앞톱니근의 선택적인 활성을 가져온 결과라고 생각한다. 또 한 Shim 등 ${ }^{23}$ 은 위와 같은 결과는 앞톱니근의 선택적 강화를 위하여 효과적인 운동의 결과라고 시사한 바와 같은 맥락으로 해석을 할 수 있다. 아울러 위 등세모근의 과도한 활성은 어깨뼈의 불안정성을 초 래하고 큰가슴근의 활성을 너무 증가시키지 않도록 운동을 하는 것 이 효율적이라고 한 기존 선행 연구를 증명하는 것으로 생각된다. 또 한 앞톱니근의 활성도 증가와 위 등세모근의 활성도 감소의 운동은 어깨의 기능 장애를 해결하는데 중요한 요소라고 하였다.2,10,2728

따라서 본 연구는 날개 어깨뼈를 경험하고 있는 20 대 대학생들을 대상으로 바로 누운 자세에서 어깨 $90^{\circ}$ 굽힘과 수평 벌림 $60^{\circ}$ 위치에 서 어깨 내밈 운동시에 4 가지 무게 none, $1 \mathrm{~kg}, 1.5 \mathrm{~kg}, 2 \mathrm{~kg}$ 의 덤벨을 들 고 앞톱니근의 효과적인 활성을 일으키는 무게를 알아보기 위하여 진행하였다. 결과적으로 무게가 증가할수록 앞톱니근과 큰가슴근의 활성도에 유의한 차이를 확인하였으며 특히 앞톱니근의 상대적으로 높은 활성도를 확인하였다. 또한 위 등세모근과 앞톱니근의 활성도 비율에서도 유의한 차이를 확인하였다. 특히 어깨 내밈 운동시에 앞 톱니근의 활성도를 증가시키고 위 등세모근의 활성도를 감소 시키기 위하여 바로 누운 자세에서 어깨 $90^{\circ}$ 굽힘과 수평 벌림 $60^{\circ}$ 에서 덤벨 무게 $2 \mathrm{~kg}$ 를 이용하여 어깨 내밈 운동을 하는 것이 날개 어깨뼈 대상 자들에게 가장 효율적인 운동이라고 생각한다. 그러나 본 연구는 몇 가지 제한점이 존재한다. 첫째 대상자 수가 적고 젊은 20대 날개 어깨 뼈 환자들을 대상으로 실시하였기에 다른 연령대 및 다양한 어깨 불 안정성에 적용하기에는 무리가 있다. 둘째 날개 어깨뼈의 진단을 보 다 객관적인 방법인 X-ray를 통한 진단방법과 어깨 관절 가동범위 측 정 등의 추가적인 측정방법이 적용되어야 하며 운동 전과 후의 날개 어깨뼈의 변화비교가 이루어지지 못한점이 있다. 셋째 즉각적인 효 과를 알아보았기에 근력이 강화되는 충분한 시간을 고려한 중재기간 의 약점이 존재한다. 마지막으로 각 대상자들의 최대반복(repetition maximum) 횟수를 고려하지 않은 일관적인 외부저항의 무게 적용 및 본 연구의 외부 저항보다 더 강한 외부 저항의 적용부분도 제한점으 로 존재한다. 따라서 추후에는 본 연구의 제한점들을 수정 및 보완하 여 어깨 기능장애에 있어 효과적인 운동프로그램의 임상적인 접근 방법을 위한 추가적인 연구가 진행되어야 하겠다. 


\section{References}

1. Andrews DW. Cross-section regression with common shocks.Econometrica, 2005;73(5):1551-85.

2. Ludewig PM, Hoff MS, Osowski EE et al. Relative balance of serratus anterior and upper trapezius muscle activity during push-up exercises. Am J Sports Med. 2004;32(2):484-93.

3. Struyf F, Nijs J, De Coninck K et al. Clinical assessment of scapular positioning in musicians: an intertester reliability study. J Athl Train. 2009;44(5):519-26.

4. Lear LJ, Gross MT. An electromyographical analysis of the scapular stabilizing synergists during a push-up progression. J Orthop Sports Phys Ther. 1998;28(3):146-57.

5. Mottram SL. Dynamic stability of the scapula. Man Ther. 1997;2(3):12331.

6. Cools AM, Struyf F, De Mey K et al. Rehabilitation of scapular dyskinesis: from the office worker to the elite overhead athlete. Br J Sports Med. 2013:48(8);692-7.

7. Smith D, Riel J, Tilles I et al. Intravenous epinephrine in life-threatening asthma. Ann Emerg Med. 2003;41(5):706-11.

8. Ekstrom RA, Bifulco KM, Lopau CJ et al. Comparing the function of the upper and lower parts of the serratus anterior muscle using surface electromyography. J Orthop Sports Phys Ther. 2004;34(5):235-43.

9. Kim ER, Oh JS, Yoo WG. Effect of vibration frequency on serratus anterior muscle activity during performance of the push-up plus with a redcord sling. J Phys Ther Sci. 2014;26(8):1275-6.

10. Cools AM, Dewitte V, Lanszweert F et al. Rehabilitation of scapular muscle balance: which exercises to prescribe?. Am J Sports Med. 2007; 35(10):1744-51.

11. Weon JH, Oh JS, Cynn HS et al. Influence of forward head posture on scapular upward rotators during isometric shoulder flexion. J Bodyw Mov Ther. 2010;14(4):367-74.

12. Koh EK, Weon JH, Jung DY. The comparison of electromyographic ratio of serratus anterior and upper trapezius according to exercise position and shoulder flexion angle during scapular protraction exercises. KJSB. 2012;22(2):193-9.

13. Ki HS, Kwon OY, Yi CH et al. Effects of the scapular taping on the muscle activity of the scapula rotators and pain in subjects with upper trapezius pain. Phys Ther Korea. 2010;17(1):77-85.

14. Jo YJ. Analytic comparison of trapezius and serratus anterior activities depending on shoulder complex movement. Korea University. Dissertation of Master's Degree. 2014.
15. Decker MJ, Hintermeister RA, Faber KJ et al. Serratus anterior muscle activity during selected rehabilitation exercises. Am J Sports Med. 1999;27(6):784-91.

16. Moseley JB Jr, Jobe FW, Pink M et al. EMG analysis of the scapular muscles during a shoulder rehabilitation program. Am J Sports Med. 1992;20(2):128-34.

17. Kim TH, Park HK. The comparison for serratus anterior muscle activity during protraction in open chain and closed chain exercises in healthy adults. J KEMA. 2018;2(1):1-5.

18. Lim JY. The effects of closed and open kinematic chain exercises for scapular winging. Daegu University. Dissertation of Master's Degree. 2010 .

19. Cram JR, Ksamann GS, Holtz. Cram`s introduction to surface electromyography. 2nd ed. Jones and Bartlett, 2010:65-70.

20. Kendall FP ME, Provance PG. Muslces: testing and function. 4th ed. USA, Williams \& Wilkins, 1993:318-332.

21. Park SK, Park JM, Lee JH. Effects of a push-up plus exercise program on scapular position and muscle activity in individuals with rounder shoulder posture. J Kor Phys Ther. 2010;22(5):1-8.

22. Moon SJ, Kim TH, Roh JS. A comparison of the serratus anterior muscle activity according to the shoulder flexion angles in a closed kinetic chain exercise and an open kinetic chain exercise. J Korean Soc Phys Med. 2013;8(3):369-78.

23. Shim YH, Nam KS, Park JW. Glenohumeral joint rotation on serratus anterior, pectoralis major and upper trapezius EMG activity during push-up plus exercise. J Kor Phys Ther. 2016;28(2):106-11.

24. Park KM, Cynn HS, Yi CH et al. Effect of isometric horizontal abduction on pectoralis major and serratus anterior EMG activity during three exercises in subjects with scapular winging. J Electromyogr Kinesiol. 2013;23(2):462-8.

25. Yoon JY KT, Oh JS. Effect of hand positions in electromyographic activity in scapulothoracic muscles during push-up plus. J Phys Ther Korea. 2010;17(4):8-15.

26. Uhl TL, Carver TJ, Mattacola CG et al. Shoulder musculature activation during upper extremity weight-bearing exercise. J Orthop Sports Phys Ther. 2003;33(3):109-17.

27. Martins J, Tucci HT, Andrade R et al. Electromyographic amplitude ratio of serratus anterior and upper trapezius muscles during modified pushups and bench press exercises. J Strength Cond Res. 2008;22(2):477-84.

28. Kim GH, Choe HS, Lee HI et al. The effects of scapular stabilization exercising on dynamic standing balance in stroke patients. J Kor Phys Ther. 2014;26(1):15-20. 